\title{
STABILITY OF STONE- AND DOLOS-ARMORED RUBBLE-MOUND BREAKWATER HEADS SUBJECTED TO BREAKING AND NONBREAKING WAVES WITH NO OVERTOPPING
}

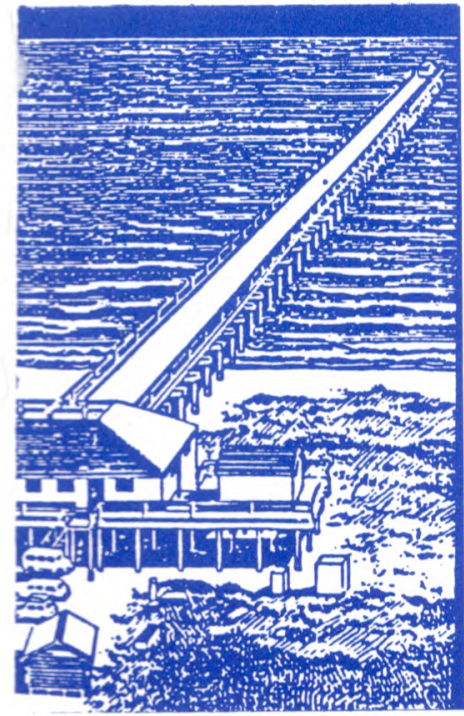

by

Robert D. Carver, Martha S. Heimbaugh

Coastal Engineering Research Center

DEPARTMENT OF THE ARMY

Waterways Experiment Station, Corps of Engineers

PO Box 631, Vicksburg, Mississippi 39181-0631
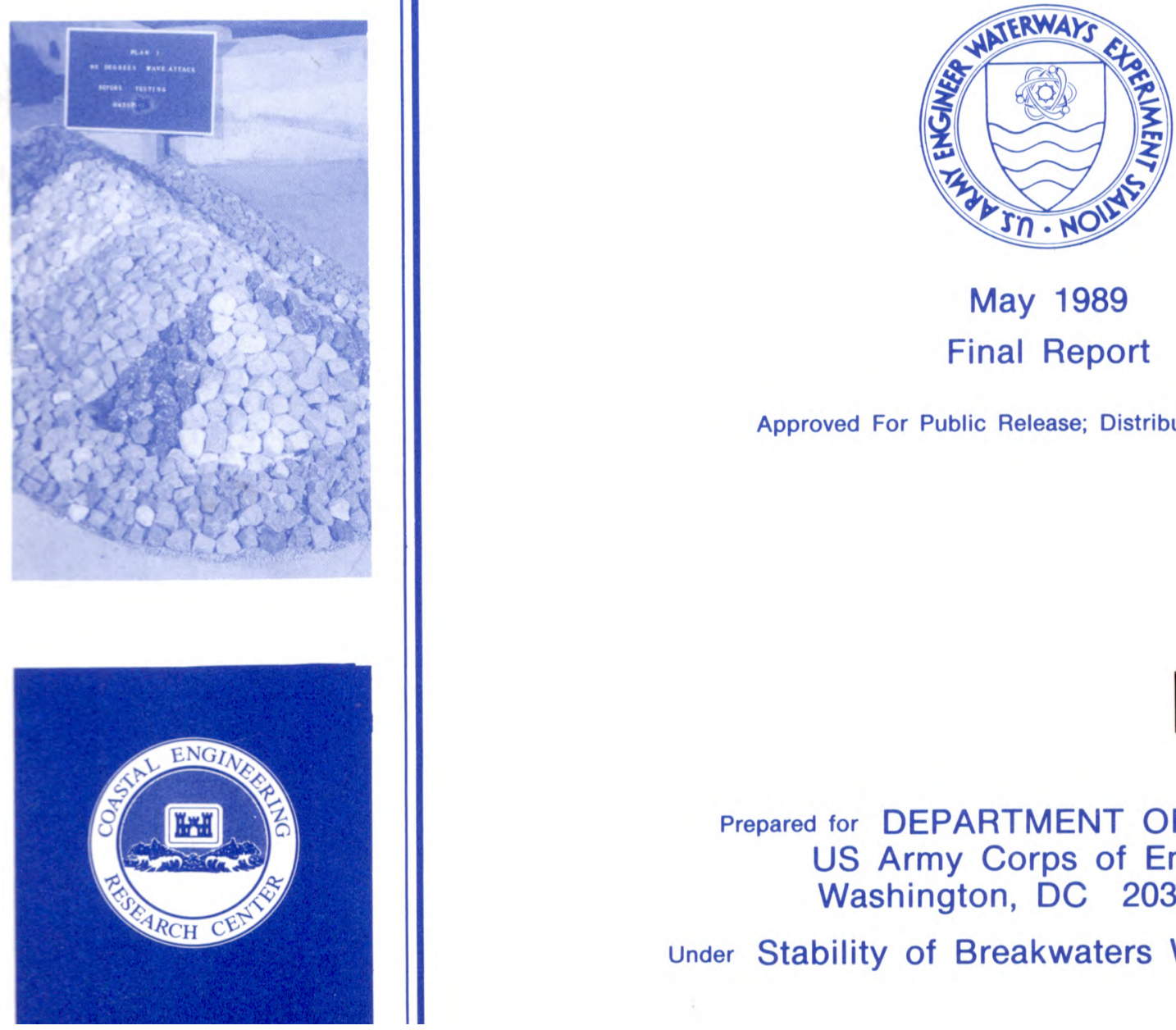

Approved For Public Release; Distribution Unlimited

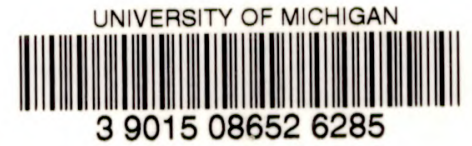

Prepared for DEPARTMENT OF THE ARMY

US Army Corps of Engineers

Washington, DC 20314-1000

Under Stability of Breakwaters Work Unit 31269 